\title{
Efficacy of percutaneous vertebroplasty for the relief of osteoblastic spinal metastasis pain
}

\author{
SONGFENG XU ${ }^{1,2}$, TING LIU ${ }^{1}$, XINXIN ZHANG ${ }^{1}$, HUANMEI LIU ${ }^{1}$, \\ ZHENGUO ZHAO ${ }^{1}$, LIBIN XU ${ }^{1}$ and SHENGJI YU ${ }^{1}$
}

\begin{abstract}
${ }^{1}$ Department of Orthopedics, National Cancer Center/National Clinical Research Center for Cancer/Cancer Hospital, Chinese Academy of Medical Science and Peking Union Medical College, Beijing 100021; ${ }^{2}$ Department of Orthopedics, National Cancer Center/National Clinical Research Center for Cancer/Cancer Hospital and Shenzhen Hospital, Chinese Academy of Medical Science and Peking Union Medical College, Shenzhen, Guangdong 518116, P.R. China
\end{abstract}

Received April 19, 2020; Accepted March 17, 2021

DOI: $10.3892 /$ etm.2021.10159

\begin{abstract}
The aim of the present manuscript was to retrospectively evaluate the efficacy of fluoroscopy-guided percutaneous vertebroplasty (PVP) for the relief of osteoblastic spinal metastases pain. PVP was performed in 39 consecutive patients with 82 osteoblastic metastatic spinal vertebras. 19 vertebras had pathologic compressive fracture and the other 63 vertebras had no compressive fracture with obvious imaging abnormalities. The ages of the patients ranged from 40 to 77 years with a mean age of $58.5 \pm 9.0$ years. Visual analog scale (VAS) and QLQ-BM22 score were used to evaluate pain and quality of life at 2 days pre-operation and at 1 week and 3 months post-operation. Among all 82 vertebras, 35 vertebras had been injected bilaterally and the other 47 vertebras unilaterally. The amount of cement injected per lesion ranged from 0.5 to $4.5 \mathrm{ml}$ with a mean volume of $1.6 \pm 0.8 \mathrm{ml}$. Cement deposition in all lesions was uniform. The patients were followed up from 3 to 15.5 months with a mean follow up time of 5.6 \pm 3.4 months. Mean VAS score declined significantly from preoperative $4.3 \pm 2.4$ to postoperative $3.0 \pm 1.7$ at 1 week and $2.4 \pm 2.0$ at 3 months after the procedure $(\mathrm{P}=0.001)$. Mean QLQ-BM22 score declined significantly from preoperative $49.1 \pm 12.3$ to postoperative $42.4 \pm 9.5$ at 1 week and $39.6 \pm 10.4$ at 3 months after the procedure $(\mathrm{P}<0.001)$. Extraosseous cement leakage occurred in 21 vertebras of 13 cases and in 1 case into the thoracic vertebra canal without causing any
\end{abstract}

Correspondence to: Professor Shengji Yu, Department of Orthopedics, National Cancer Center/National Clinical Research Center for Cancer/Cancer Hospital, Chinese Academy of Medical Science and Peking Union Medical College, 17 PanJiaYuanNanLi, Chaoyang, Beijing 100021, P.R. China

E-mail: shengjiyu@126.com

Key words: percutaneous vertebroplasty, osteoblastic spinal metastases, pain relief, visual analog scale, quality of life, QLQ-BM22 clinical complications. No further procedures were performed after leakage. PVP is an effective treatment for painful osteoblastic spinal metastases. It can relieve pain, reduce disability and improve function. The main complications are bone cement leakage and incomplete pain relief.

\section{Introduction}

Bone metastasis is a serious and costly complication of cancer and is usually incurable (1). Approximately $70 \%$ of patients with advanced breast and prostate cancers and up to 30-40\% of patients with advanced lung, thyroid and kidney cancer develop bone metastasis (2). Bone metastases may be characterized as osteolytic or osteoblastic lesions (1). Breast cancer usually forms osteolytic lesions, and $15-20 \%$ of patients with bone metastases develop osteoblastic lesions (1). By contrast, patients with prostate cancer more often develop osteoblastic lesions. Patients with multiple myeloma develop only osteolytic lesions.

Spinal metastases, which are observed in $60-70 \%$ of patients with systemic cancer, can cause severe pain (usually in $90-95 \%$ of patients with metastases), pathologic fractures, life-threatening hypercalcemia, spinal cord compression and poor quality of life (3). The goals of treating spinal metastasis are pain relief and spinal stabilization. Treatment selection is affected by numerous factors, including survival prediction, patient health, the number and localization of involved vertebrae and the degree of expansion of the spinal metastasis to the surrounding tissue. It is recommended to start spinal metastasis treatment within 14 days of symptoms being reported in cases where pain is the only symptom (3). Surgery, chemotherapy and radiotherapy may be undesirable treatment options, as duration of the required postoperative hospital stay may last much of the patient's remaining life expectancy (4).

Percutaneous vertebroplasty (PVP) and percutaneous kyphoplasty (PKP) are both minimally invasive techniques where polymethylmethacrylate (PMMA) is injected in the vertebral body under X-ray or CT guidance. PVP had been demonstrated to be an economical and effective procedure in controlling pain (usually in $74-100 \%$ of patients) and preventing further vertebral collapse in spinal metastases and 
also allows for percutaneous biopsy $(3,5,6)$. Although PVP has been widely used in treatment of osteolytic metastases, there have been a few reports on the effect of PVP in painful osteoblastic metastatic spinal lesions (7-10).

In the present study, the clinical data of patients treated with PVP following painful osteoblastic spinal metastases were retrospectively analyzed.

\section{Materials and methods}

Study design. The present study is a retrospective analysis of data obtained from 39 consecutive patients with 82 osteoblastic vertebras who developed painful spinal metastases. These patients were referred to the Department of Orthopedics of the Cancer Hospital of the Chinese Academy of Medical Science between August 2017 and February 2019.

Inclusion and exclusion criteria. Patients had to meet the following inclusion criteria: i) Diagnosed with cancer; ii) aged 18-80 years; iii) clinical and imaging evidence (MRI or CT) of vertebral metastases in the cervical, thoracic, lumbar or sacral segments; iv) osteoblastic appearance of metastases and excruciating pain corresponding with specific vertebral levels, despite pharmacological treatment, or adverse effects related to opioids (constipation, urinary retention and/or confusion), or opioid tolerance developed in patients with controlled pain; v) patients treated with spine radiotherapy or waiting to receive radiotherapy sessions; vi) expected survival time $>3$ months; and vii) vertebral fractures without posterior wall disruption, or fractures with posterior wall disruption but no epidural involvement.

Exclusion criteria included patients with: i) Clinical signs of spinal cord compression or cauda equina syndrome; ii) fractures with epidural involvement and contact with spinal cord or nerve roots; iii) complete vertebral destruction; iv) posterior arch involvement and v) local infection at the puncture site or septicemia. Relative contraindications included transient chemotherapy-induced hematologic anomalies, including leucopenia $\left(<2.5 \times 10^{3} / \mu 1\right)$, thrombocytopenia $\left(<100.0 \times 10^{3} / \mu 1\right)$ and c) elevated international normalized ratio $>1.5$. Only those patients whose abnormalities had resolved underwent PVP.

Clinical information was obtained through electronic medical records while imaging was obtained from the hospital picture archiving and communication system. CT or MR images were evaluated. Data including primary tumor site, age of spinal metastases, date of the procedure, modality of associated chemotherapy and radiotherapy, pain assessment of spinal metastases, vertebral level treated, technical incidents and details of complications, such as patients drop out from follow-up were recorded.

The visual analogue scale (VAS) score was used to evaluate pain intensity before PVP procedures and at 1 week and 3 months after the procedure. The VAS assesses pain level on a scale of $0-10$, with 0 being no pain and 10 indicating the worst pain (11). To assess quality of life the EORTC QLQ-BM22 module was used, which contains 22 items conceptualized into symptom scales (five painful sites and three pain characteristics) and functional scales (eight functional interference) and six psychosocial aspects (12). QLQ-BM22 scores were recorded by the attending oncologist before PVP and at 1 week and 3 months after PVP.
The technique of PVP has been described in detail elsewhere $(13,14)$ and official guidelines have also been published $(15,16)$. PVP involves a biopsy through a transpedicle approach and the injection of polymethylmethacrylate (PMMA) into the vertebral body. All PVP procedures were performed by senior orthopedists with $>10$ years of experience of performing the PVP procedure, always using a digital subtraction angiography unit with a C-arm (Angiostar, Siemens). The patient was under conscious sedation in combination with local anaesthesia with lidocaine $1 \%$ at pedicle levels (transpedicular approach) administered by fluoroscopic guidance. General anaesthesia with orotracheal intubation was used when the patient was unable to be in the prone position, as well as when the anesthesiologist considered it necessary. The bone needle (11-13G; WEGO, Inc.) was used to slowly puncture the anterior one third of the vertebral body through a posterior transpedicular approach under fluoroscopic guidance. The trocar was removed and a biopsy device placed to obtain a bone core. Then the polymethyl methacrylate (PMMA) cement (SimplexP; Howmedica Osteonics Corporation) was injected into the cavity within the vertebral body avoiding the osteoblastic lesion. The injection process was monitored continuously under fluoroscopy in the lateral plane. Injection was stopped when substantial resistance was met or when the PMMA cement reached the posterior margin of the vertebral body.

At the end of the procedure the presence of cement leakage to the vertebral disk, anterolateral, lateral, foraminal and epidural veins, paravertebral plexus, vena cava, intercostal arteries, soft tissue or spinal canal was recorded. All complications were recorded in the database, including haematoma, radicular pain and pulmonary embolism due to cement migration and settlement in the pulmonary vasculature (confirmed by $\mathrm{CT}$ in all suspicious cases).

Statistical analysis. Descriptive statistical analysis was performed on all assessed variables. VAS was evaluated preoperatively and at 1 week and 3 months after the surgery. Quality of life (QOL) was evaluated with QLQ-BM22 score (12) in the studied population before the surgery and at one week and 3 months after the surgery. All statistical analyses were performed using SPSS for Windows version 22.0 (SPSS, Inc). Data are presented as the median \pm SD for the VAS and QLQ-BM22 score at different time points. The Wilcoxon signed rank test was used to compare the median VAS and QLQ-BM22 scores at the different study time point after surgery versus pre-operation. $\mathrm{P}<0.05$ was considered statistically significant.

\section{Results}

PVP was performed for 39 consecutive patients with 82 osteoblastic metastatic spinal vertebras, of which 19 vertebras had pathologic compressive fracture sand the other 63 vertebras had no compressive fracture with obvious imaging abnormalities. Among all 82 vertebras, 35 vertebras had been injected bilaterally and the other 47 vertebras unilaterally. The patients were 19 males and 20 females with a mean age of 58.5 years (age range, 40-77 years; Figs 1-3). The postoperavie pathological diagnoses of spinal metastases were all malignant: 14 

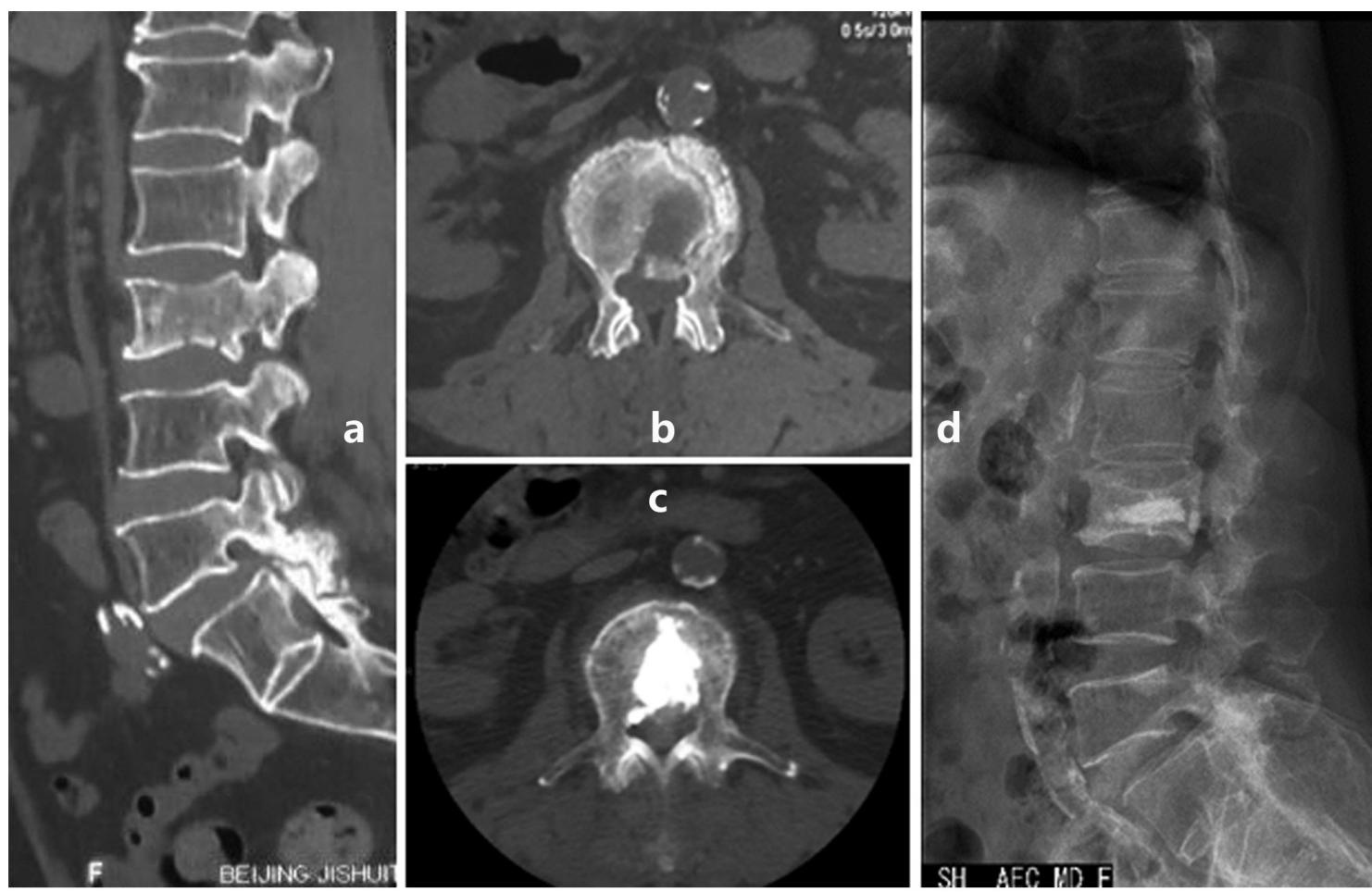

Figure 1. Case 1. (a and b) A 78-year-old male patient with an isolated osteoblastic spinal metastasis in the 3rd lumbar vertebrae after prostate cancer treatment. (c and d) After treatment with percutaneous vertebroplasty, at 3 months the visual analogue score decreased from 5 to 2, and QLQ-BM22 score decreased from 55 to 34 .

A

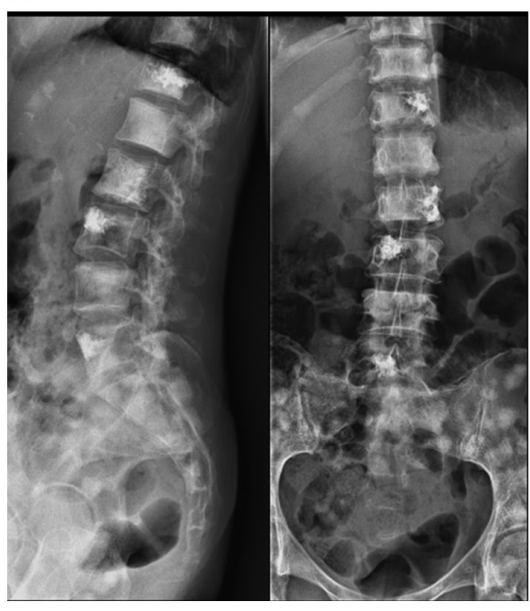

B
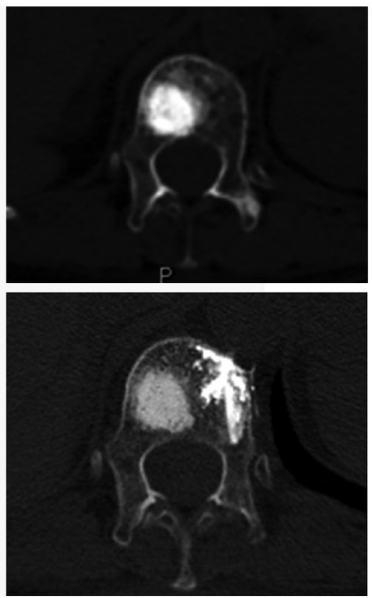

C

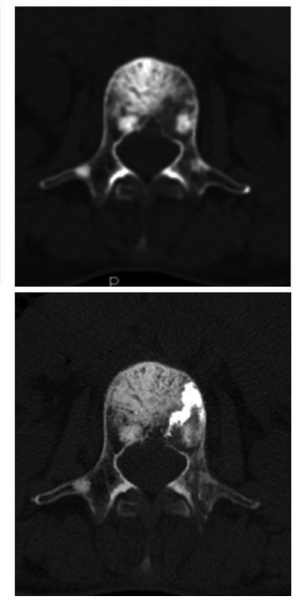

D

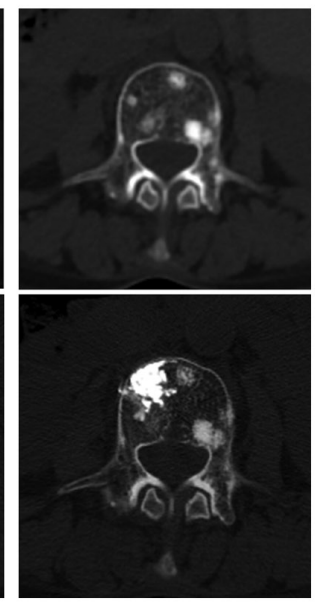

Figure 2. Case 2. A 57-year-old female patient with (A) multiple osteoblastic spinal metastasis (B) in T12, (C) L1 and (D) L3 vertebras after 2-years' treatment for lung cancer. After the treatment with percutaneous vertebroplasty the 3 month visual analogue score decreased from 6 to 1, and QLQ-BM22 score decreased from 73 to 51 .

with lung cancer, 10 with breast cancer, 4 with kidney cancer, 4 with colon cancer, 1 with esophageal cancer, 1 with gastric cancer, 1 with ovarian cancer, 1 with prostate cancer, 1 with salivary gland carcinoma and 2 with unknown malignancies. The amount of cement injected per lesion ranged from 0.5 to $4.5 \mathrm{ml}$ with a mean volume of $1.6 \pm 0.8 \mathrm{ml}$. Cement deposition in all lesions was uniform.

The patients were followed up from 3 to 15.5 months with a mean follow up time of 5.6 \pm 3.4 months. Mean VAS score declined significantly from preoperative $4.3 \pm 2.4$ to postoperative $3.0 \pm 1.7$ at 1 week $(\mathrm{P}=0.009)$ and $2.4 \pm 2.0$ at 3 months after the procedures ( $\mathrm{P}=0.002$; Fig. 4). Mean QLQ-BM22 score declined significantly from preoperative $49.1 \pm 12.3$ to postoperative $42.4 \pm 9.5$ at 1 week $(\mathrm{P}=0.001)$ and $39.6 \pm 10.4$ at 3 months after the procedure $(\mathrm{P}<0.001$; Fig. 5$)$. Extraosseous cement leakage occurred in 21 vertebras of 13 patients and in 1 case into the thoracic vertebra canal without causing any clinical complications. No further procedures were performed after leakage.

\section{Discussion}

Patients with bone metastases are at risk of suffering due to severe symptoms such as bone pain and life-threatening hypercalcemia, 
Table I. Reports forcusing minimally invasive surgery in osteoblastic spinal metastasis.

\begin{tabular}{|c|c|c|c|c|c|c|c|c|}
\hline \multirow[b]{2}{*}{ Author } & \multirow[b]{2}{*}{ Year } & \multirow{2}{*}{$\begin{array}{l}\text { Minimally } \\
\text { invasive } \\
\text { surgery }\end{array}$} & \multicolumn{2}{|c|}{ Cohort Size } & \multirow{2}{*}{$\begin{array}{c}\text { Lesion site } \\
\text { (cement volume) }\end{array}$} & \multirow{2}{*}{$\begin{array}{l}\text { Primary tumor } \\
\text { (number) }\end{array}$} & \multirow{2}{*}{$\begin{array}{l}\text { Follow-up } \\
\text { duration }\end{array}$} & \multirow[b]{2}{*}{ Assessment } \\
\hline & & & Case & Control & & & & \\
\hline Murphy et al (7) & 2007 & PVP & 1 & 0 & T10 (Not mentioned) & Breast cancer (1) & 3 years & None \\
\hline Chen et al (39) & 2011 & PVP & 4 & 0 & $\begin{array}{l}\text { Thoracic and lumbar } \\
\text { vertebra }(2.2-3.5 \mathrm{ml})\end{array}$ & $\begin{array}{l}\text { Lung (2), } \\
\text { Prostate (1) and } \\
\text { Pancreatic (1) Cancer }\end{array}$ & 14-24 weeks & VAS \\
\hline Chen et al (41) & 2013 & PKP & 6 & 0 & $\begin{array}{l}\text { Thoracic and lumbar } \\
\text { vertebra }(3.3 \pm 1.0 \mathrm{ml})\end{array}$ & $\begin{array}{l}\text { Lung ( } 2), \text { breast ( } 2) \text {, } \\
\text { liver ( } 1) \text { and } \\
\text { prostate (1) cancer }\end{array}$ & 16-96 weeks & VAS, ODI \\
\hline Yang et al (8) & 2013 & PVP and ${ }^{125} \mathrm{I}$ & 50 & 50 & $\begin{array}{l}\text { Thoracic }(2.8 \mathrm{ml}) \text { and } \\
\text { lumbar }(3.1 \mathrm{ml}) \\
\text { vertebra }\end{array}$ & $\begin{array}{l}\text { Lung }(20) \text {, } \\
\text { breast (19), prostate } \\
\text { (10) and colon } \\
\text { (1) cancer }\end{array}$ & $\begin{array}{l}6 \text { months-5 } \\
\text { years }\end{array}$ & $\begin{array}{l}\text { VAS ECOG } \\
\text { (QLQ-C30) }\end{array}$ \\
\hline Chih et al (9) & 2016 & PVP & 1 & 0 & $\mathrm{~L} 2(5 \mathrm{ml})$ & $\begin{array}{l}\text { Pancreatic } \\
\text { Cancer (1) }\end{array}$ & 1 year & VAS ECOG \\
\hline Tian et al (10) & 2016 & PVP & 39 & 0 & $\begin{array}{l}\text { Thoracic and lumbar } \\
\text { vertebra }(2-5 \mathrm{ml})\end{array}$ & $\begin{array}{l}\text { Lung (15), } \\
\text { prostate (11) breast (9), } \\
\text { liver (3), and colon (1) } \\
\text { cancer }\end{array}$ & 3-30 months & KPS \\
\hline
\end{tabular}

PVP, percutaneous vertebroplasty; VAS, visual analogue score; ECOG, Eastern Cooporative Oncology Group; KPS, Karnofsky Performance Score, ODI, Oswestry Disability Index.
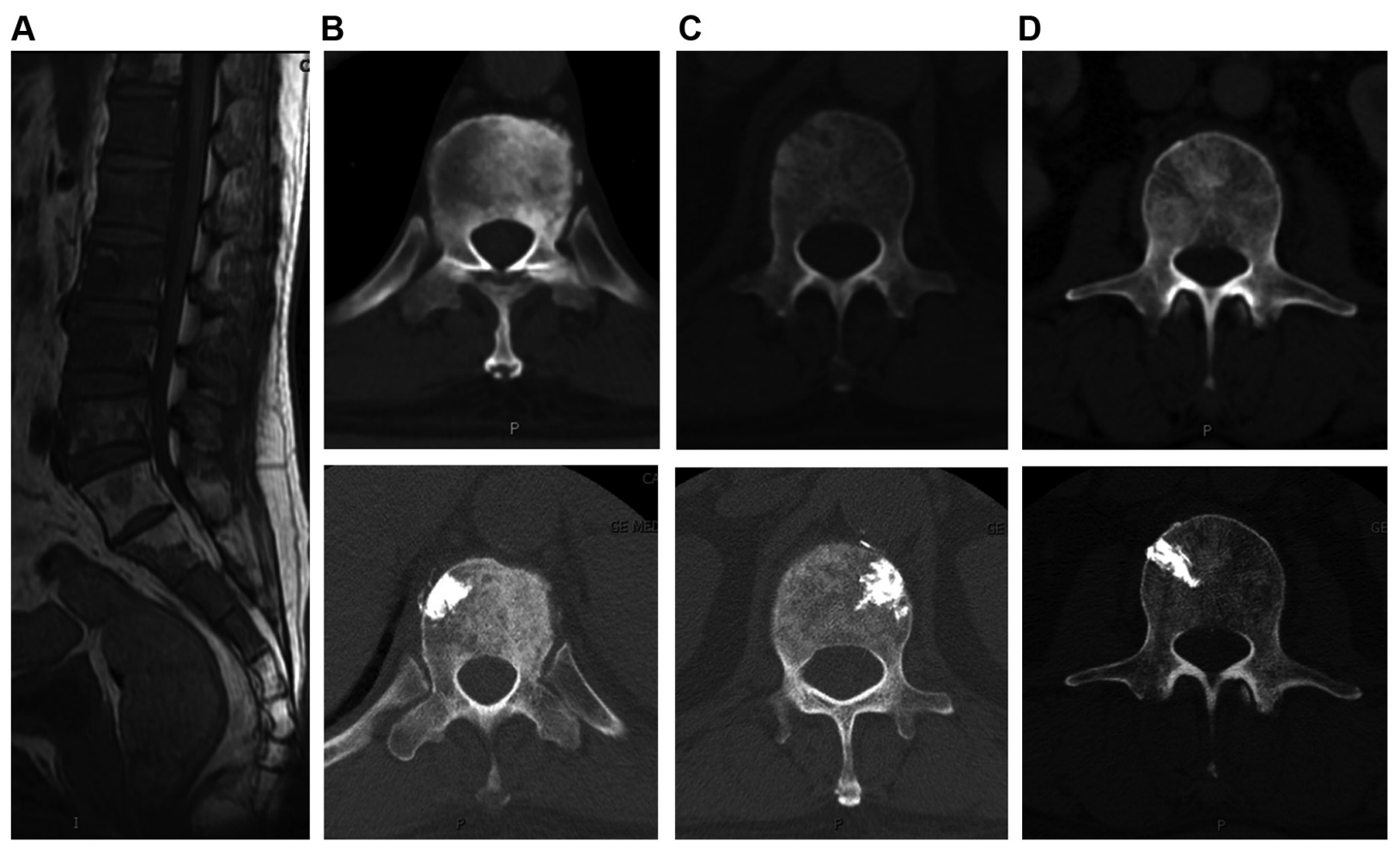

Figure 3. Case 3. A 54-year-old male patient with (A) multiple osteoblastic spinal metastasis (B) in T11, (C) L1 and (D) L3 vertebras after 1-years' treatment for lung cancer. 3 months after the treatment with percutaneous vertebroplasty t, visual analogue score decreased from 6 to 2, and QLQ-BM22 score decreased from 57 to 36 .

pathological fracture, neurological deficit and epidural spinal cord compression $(17,18)$. Therefore, providing appropriate pain relief by minimally invasive surgery to improve patient quality of life is of importance and also a major challenge for these patients. 


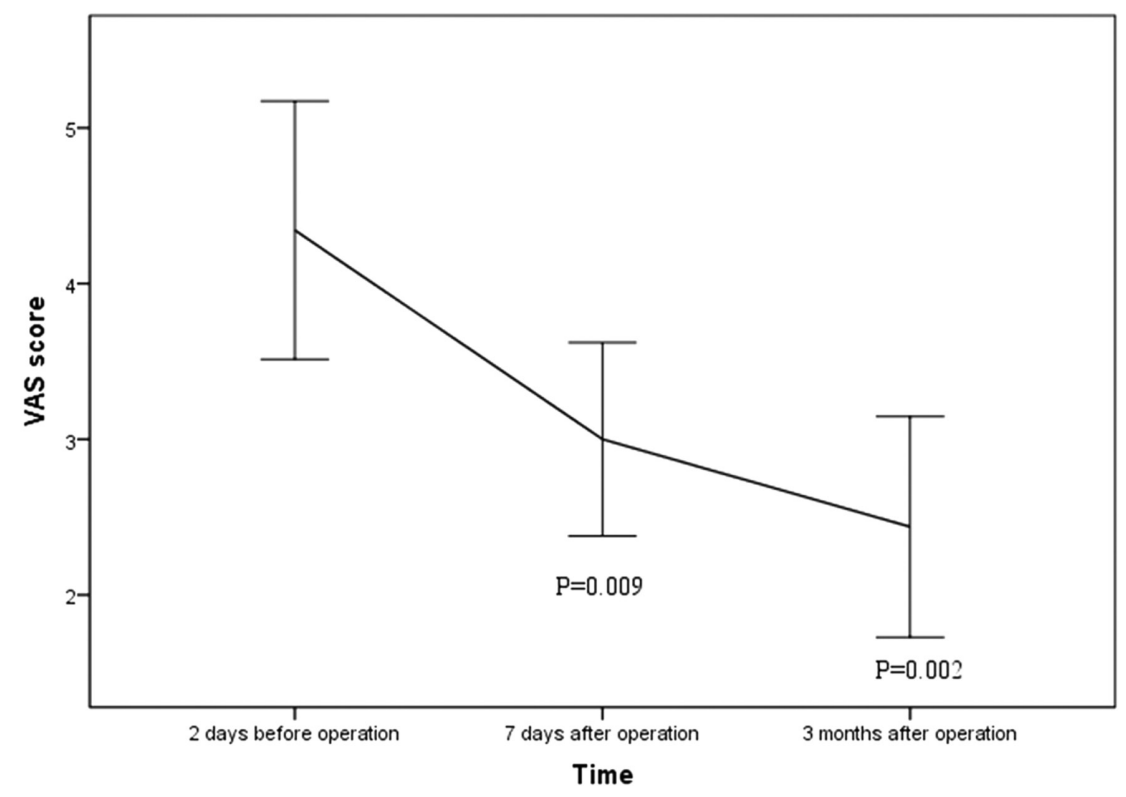

Figure 4. Mean VAS scores. The mean VAS scores declined significantly from preoperative $4.3 \pm 2.4$ to postoperative $3.0 \pm 1.7$ at 1 week and $2.4 \pm 2.0$ at 3 months after the procedure $(\mathrm{P}=.001)$. Pain relief increased gradually with time. VAS, visual analogue score.

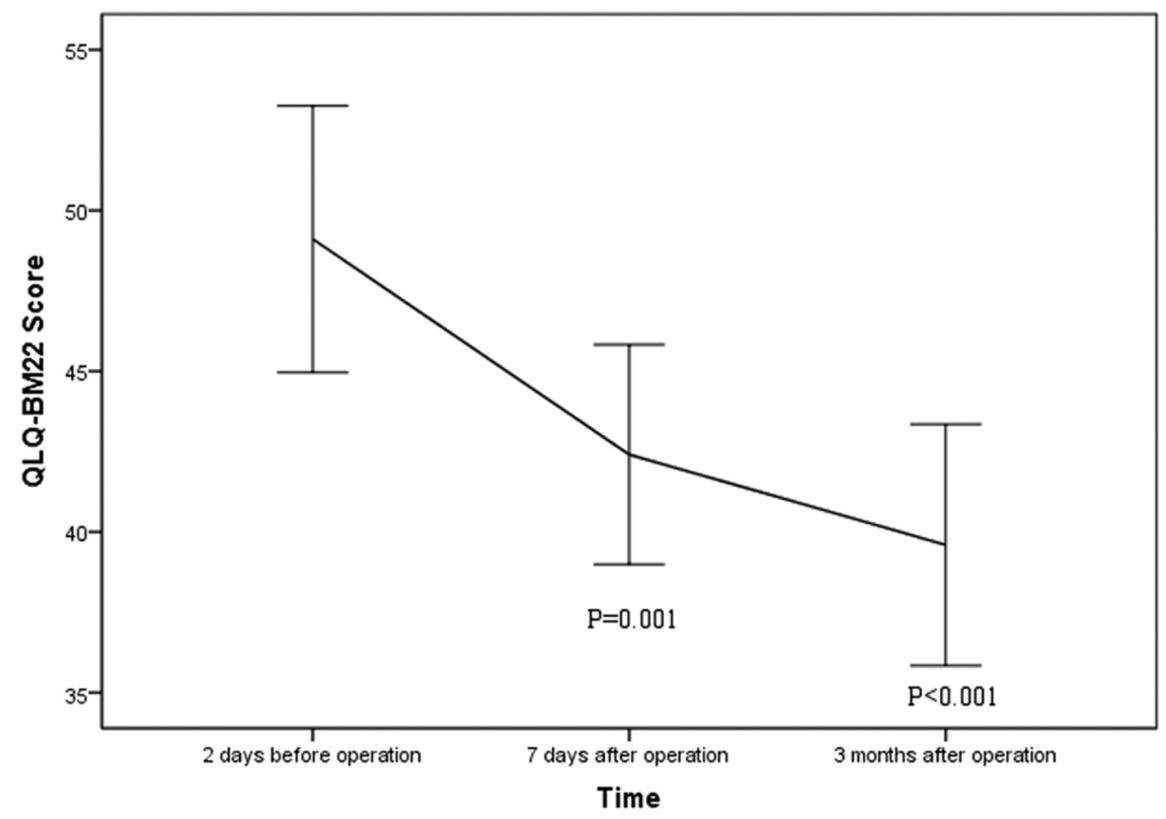

Figure 5. Mean QLQ-BM22 scores. The mean QLQ-BM22 scores declined significantly from preoperative $49.1 \pm 12.3$ to postoperative $42.4 \pm 9.5$ at 1 week and $39.6 \pm 10.4$ at 3 months after the procedure $(\mathrm{P}<0.001)$. Quality of life increased gradually with time.

Bone metastases can be characterized as osteolytic or osteoblastic lesions (1). These classifications represent two extremes of a continuum in which dysregulation of the normal bone remodeling process occurs (19). In addition, secondary formation of bone occurs in response to bone destruction. The mechanisms of osteoblastic metastasis and the factors involved are unknown. Previous research $(11,20,21)$ has suggested that blocking osteoblast-stimulating activity by tumor cells may decrease tumor growth and osteoblast activity, which suggests that a cycle may be involved in osteoblastic metastasis in which tumors induce osteoblast activity and thus the subsequent release of growth factors from these osteoblasts that increase tumor growth.
The histology of the tumor-bone interface in both humans and mouse models of tumor bone colonization reveals much about the cellular content and context of the bone marrow in the presence of metastatic tumor cells (22). Endothelin-1 (20), platelet-derived growth factor (23), urokinase (24) and prostate-specific antigen (PSA) (25) have been identified to be involved in osteoblastic metastasis process. Bone metastases caused by prostate cancer are commonly osteoblastic, with levels of bone-resorption markers higher in patients with these metastases than in patients without bone metastasis. The extent of bone metastasis in these patients is more accurately measured in these patients by bone-resorption markers than the PSA level (26). It is still 
unclear whether bone resorption precedes bone formation in the development of osteoblastic metastases. The antiosteolytic action of drugs, including bisphosphonates (27), has led to the evaluation of their use in prostate cancer, which demonstrated their efficacy in patients with hormone-refractory metastatic prostate cancer (28). Bone-protection agents, including bisphosphonates and denosumab $(29,30)$, lead to a reduction in osteoclastic activity and induction of apoptosis, inhibiting bone resorption as well as inhibiting tumor cell adhesion to bone (18). This could ultimately control pain relief, even in osteoblastic metastasis $(18,31)$. Emerging agents targeting osteoblasts, such as romosozumab, can activate bone formation (32). These drugs may improve bone formation and indirectly be involved in osteoblastic metastatic processes.

Patients with spinal metastases are highly likely to achieve significant improvements in pain control and reduced pain-related disability through minimally-invasive surgery (33-35). Previous reports published on minimally invasive surgery in spinal metastasis were largely focused on osteolytic metastasis. Improvements in preoperative definable vertebral collapse (36) and postoperative pain relief and QOL were demonstrated (33). Both PVP and PKP are effective, and no difference could be found in their relative effectiveness $(37,38)$. PVP could achieve pain relief and improvement of life quality of patients with multiple myeloma spinal metastasis (33). Concerning the subsequent cost dure to the care requirements and serious clinical consequences of spinal metastasis, the use of PVP could be a cost-effective strategy at commonly accepted willingness-to-pay thresholds (35). The mechanism of pain relief by PVP in vertebral compressive fracture is that PMMA mechanically stabilizes the vertebral body and its fragments causing an exothermic reaction during the polymerization of the cement and a neurotoxic effect to the surrounding micronerves (4). Considering the rarity of local recurrence of metastatic tumors after PVP, it has been hypothesized that PVP may have an antitumoral effect by the space occupying effect and the vascular structure destruction related to PMMA (4).

Although PVP has been widely used in treatment of osteolytic metastases, few published reports are focused on osteoblastic metastasis (7-10,39-41) (Table I), the findings of which are summarized here. In 39 consecutive patients with 51 osteoblastic metastases, vertebroplasty could relieve pain, reduce disability, and improve function (10). Immediate pain relief was achieved in 4 patients with painful osteoblastic spinal metastases (39). A total of $86 \%$ of patients with osteoblastic metastases experienced pain relief up to $92 \%$ at 6 months after PVP procedure (40). A contralateral unipedicular approach was suggested to access the vertebral body and strengthen the nonblastic side of the metastasic vertebra body, which might lead to bone pain relief (7). In 6 patients with painful osteoblastic metastases, pain relief and function improvement was been achieved after PKP procedure without any complications (41). A combination of PVP and ${ }^{125} \mathrm{I}$ implantation was conducted for 50 patients with spinal osteoblastic metastases, which showed clinical efficacy with immediate pain relief, QOL improvement and reduction of paraplegia occurrence (8). However, the PVP attempt failed in a patient with a painful lytic vertebral fracture related to a lung cancer spinal metastasis under medical treatment with denosumab, which induced a fast and marked sclerotic response on vertebral bodies that may not be accompanied by a satisfactory improvement in pain control (42). These findings raised the question of the optimal treatment order and the best timeframe for combination of PVP and bone protection agents in patients with painful spinal metastases.

Pain relief. The treatment choices available for painful metastases are varied (5). The Dutch National Guideline noted that surgical techniques range from minimally invasive options to en bloc resection of the segments affected by spinal metastases (3). The injection of bone cement may stabilize the vertebrae and prevent further collapse of the osteoblastic vertebral body. In osteobalstic metastasis, it also hypothesized that the asymmetry of vertebral oeteoblastic compressibility might result in shear stress fractures causing pain, which could be equalized by vertebroplasty into the nonblastic side (7). A meta-analysis with 26 studies involving 1,351 patients with PVP treatment for spinal tumors demonstrated that PVP was significantly associated with pain relief and life quality and could improve outcomes in these metrics in metastatic spinal tumor patients (34). It is hypothesized that pain relief in osteoblastic metastasis following bone cement application is related not only the reinforcement of the vertebra, but also to chemical and thermal effects of the cement compound, which may damage sensory nerve endings and kill the tumor cells $(4,39,41)$.

Pain scores are classified as follows: VAS 1-4, mild pain; 5-8, moderate pain; and 9-10 as severe pain (43). Previous studies of osteoblastic spinal metastases showed postoperative pain relief. It has been reported that a VAS score decline could be found after PVP from preoperative $7.4 \pm 1.1$ to postoperative $2.5 \pm 0.9$ at 3 days and $2.1 \pm 1.1$ at 1 month, $2.0 \pm 1.1$ at 3 months (10), which suggested pain score was reduced from moderate to mild at 3 months after the operation. In a patient with painful osteoblastic pancreatic spinal metastases, a VAS scores decline could be found after PVP from preoperative 9-10 to postoperative 3-4 at follow-up after $<1$-year (9), which suggested pain was reduced from severe to mild. In 4 patient with painful osteoblastic spinal metastases, a VAS score decline could also be found after PVP from preoperative $8.5 \pm 0.6$ to postoperative $1.5 \pm 0.6$ at on month, which suggested a pain score reduction from severe and moderate to mild. In the present study, the VAS score declined significantly from preoperative $5.0 \pm 2.8$ to postoperative $3.0 \pm 1.7$ at 1 week and $2.4 \pm 2.0$ at 3 months $(\mathrm{P}<0.001)$, which suggested a pain reduction from moderate to mild. Minimally invasive procedurse for the stabilization of both osteoblastic and osteoclastic spinal metastases, could achieve statistically significant pain relief, function improvement, preventing further local kyphotic deformity, and vertebra body height $(40,44)$.

For patients with advanced cancer who have developed bone metastases, increased life expectancy has made metastases more observable, which has resulted in a change in treatment strategy from curative to palliative (33). Minimally invasive procedures performed after spinal metastases, including vertebroplasty and kyphoplasty, could significantly improve the patient's QOL (33). Questionnaires for 
this group of patients should be brief while still including the most important QOL issues so as not to burden the patient (45). In 2009, Chow et al (12) developed a comprehensive HRQOL measurement tool for patients with bone metastases. The EORTC QLQ-BM22 module contains 22 items conceptualized into both symptom scales, with five painful sites and three pain characteristics, and also functional scales, with eight functional interference and six psychosocial aspects (12). Compared with BOMET-QOL, QLQ-BM22 gives a more in-depth analysis of symptoms and well-being and includes issues such as mobility, side effects, complications and dependency for patients with bone metastases (46). The BOMET-QOL is shorter and gives an overall assessment of pain and mobility. Both questionnaires have been determined to be valid and reliable. In the present study QLQ-BM22 was used to measure the QOL of patients with bone metastases.

A relatively high rate of cement leakage occurred in $21 / 82$ (25.7\%) vertebras and 13/39 (33.3\%) patients, of which 2/39 $(5 \%)$ patients experienced leakage into the vertebral canal. The two patients presented with the immediate complication of radicular pain, of which one resolved within 3 days, and the other one within two weeks following treatment with oral medication. No mortality episodes, such as cement related pulmonary embolism, were recorded during the present study. These data suggested that no severe systemic complications occur following PVP in patients with osteoblastic spinal metastases.

The present study reported technical incidents related to cement leakages, but otherwise patients were asymptomatic in the immediate and follow-up post-PVP, similar to those reported by other authors. In a study with 39 consecutive patients with 51 osteoblastic metastatic spinal lesions, extraosseous cement leakage occurred in 15 cases without causing any clinical complications (10). In osteoporotic vertebral compression fractures, the most frequently reported complication of PVP was cement leakage, occurring in up to $75 \%$ of patients (47) and is usually asymptomatic (3). Low viscosity, a larger quantity of injected PMMA and greater cortical destruction of the vertebra seem to increase the risk of cement leakage (3).

The high number of cement leakages recorded in the present study could be explained by the following: a) Careful monitoring of cement distribution during the PVP procedure; b) use of CT imaging for post PVP observation; c) treatment of two or more vertebras per patient, with up to 6 vertebras; d) the treatment of osteoblastic lesions that are more prone to leakage (40); and e) a relatively high volume of cement injected per vertebra, up to $4.5 \mathrm{ml}$.

To improve clinical outcomes, it is advised to follow these approaches: i) If possible, try to use the high viscosity cement to avoid leakage, which will shorten the injection duration; ii) place the puncture needle at the place without osteoblastic side to equally strengthen the nonblastic side (Fig. 1); iii) apply unilateral injection rather than bilateral injections which is usually difficult to finish due to the osteoblastic strength (Fig. 2); and iv) use a thin trephine and a surgical hammer (Fig. 3; 10,39) to aid penetration of the transpedicular due to the hardness of the osteoblastic bone at the start of the procedure.
The present study had certain limitations. First, a control group undergoing conservative treatment was not available. Second, the number of participants was relatively small. Third, the general status, previous treatment, life expectancy, and tumor type of the cancer patient may all influence the treatment outcome. Additional high-quality data are necessary to draw more reliable conclusions.

PVP is an effective treatment for painful osteoblastic spinal metastases. It can relieve pain, reduce disability, and improve function. The main complications are bone cement leakage and unfavorable pain relief.

\section{Acknowledgements}

The authors would like to thank Professor Shao Mng Wang from the Office of Cancer Registry, National Cancer Center/National Clinical Research Center for Cancer/Cancer Hospital, Chinese Academy of Medical Science and Peking Union Medical College for her assistance with statistical analysis.

\section{Funding}

This study was supported by grants from the Beijing Municipal Science \& Technology Comission (grant no. Z171100001017210), Beijing Hope Run Special Fund of Cancer Foundation of China (grant no. LC2016L01) and Beijing Union Medical College (PUMC) Youth Fund (grant no. 2017320016)

\section{Availability of data and materials}

The datasets used and analyzed during the current study are available from the corresponding author on reasonable request.

\section{Author's contributions}

SFX and SJY confirm the authenticity of all the raw data. SFX and SJY conceived and designed the surgical plan. XXZ and HML carried out the data collection and analysis. TL, XXZ, LBX and ZGZ contributed surgery and data collection. SFX and TL contributed to the writing of the article. All authors read and approved the final manuscript.

\section{Ethics approval and consent to participate}

Not applicable.

\section{Patient consent for publication}

Not applicable.

\section{Competing interests}

The authors declare that they have no competing interests.

\section{References}

1. Roodman GD: Mechanisms of bone metastasis. N Engl J Med 350: 1655-1664, 2004. 
2. Ferreira AR, Abrunhosa-Branquinho A, Jorge M, Costa L and Vaz-Luís I: Bone metastases. In: International Manual of Oncology Practice: (iMOP)-Principles of Medical Oncology. de Mello RA, Tavares Á and Mountzios G (eds). Springer International Publishing, Cham, pp867-889, 2015.

3. Bollen L, Dijkstra SPD, Bartels R, de Graeff A, Poelma DLH, Brouwer T, Algra PR, Kuijlen JMA, Minnema MC, Nijboer C, et al: Clinical management of spinal metastases-The Dutch national guideline. Eur J Cancer 104: 81-90, 2018.

4. Yang HL, Sun ZY, Wu GZ, Chen KW, Gu Y and Qian ZL: Do vertebroplasty and kyphoplasty have an antitumoral effect? Med Hypotheses 76: 145-146, 2011.

5. O'Toole GC and Boland P: Metastatic bone cancer pain: Etiology and treatment options. Curr Pain Headache Rep 10: 288-292, 2006

6. Yang PL, He XJ, Li HP, Zang QJ and Wang GY: Image-guided minimally invasive percutaneous treatment of spinal metastasis. Exp Ther Med 13: 705-709, 2017.

7. Murphy KJ, Nwankwo IJ and Gailloud P: Percutaneous vertebroplasty in the treatment of blastic vertebral column metastasis from breast cancer. J Vasc Interv Radiol 18: 321-323, 2007.

8. Yang Z, Tan J, Zhao R, Wang J, Sun H, Wang X, Xu L, Jiang H and Zhang J: Clinical investigations on the spinal osteoblastic metastasis treated by combination of percutaneous vertebroplasty and 125I seeds implantation versus radiotherapy. Cancer Biother Radiopharm 28: 58-64, 2013.

9. Chih YP, Wu WT, Lin CL, Jou HJ, Huang YH, Chen LC and Chou LW: Vertebral compression fracture related to pancreatic cancer with osteoblastic metastasis: A case report and literature review. Medicine (Baltimore) 95: e2670, 2016.

10. Tian QH, Sun XQ, Lu YY, Wang T, Wu CG, Li MH and Cheng YS: Percutaneous vertebroplasty for palliative treatment of painful osteoblastic spinal metastases: A single-center experience. J Vasc Interv Radiol 27: 1420-1424, 2016.

11. McCormack HM, Horne DJ and Sheather S: Clinical applications of visual analogue scales: A critical review. Psychol Med 18: 1007-1019, 1988.

12. Chow E, Hird A, Velikova G, Johnson C, Dewolf L, Bezjak A, Wu J, Shafiq J, Sezer O, Kardamakis D, et al: The European organisation for research and treatment of cancer quality of life questionnaire for patients with bone metastases: The EORTC QLQ-BM22. Eur J Cancer 45: 1146-1152, 2009.

13. Deramond H, Depriester C, GalibertP and Le Gars D: Percutaneous vertebroplasty with polymethylmethacrylate. Technique, indications, and results. Radiol Clin North Am 36: 533-546, 1998.

14. Mansoorinasab $\mathrm{M}$ and Abdolhoseinpour $\mathrm{H}$ : A review and update of vertebral fractures due to metastatic tumors of various sites to the spine: Percutaneous vertebroplasty. Interv Med Appl Sci 10: $1-6,2018$.

15. McGraw JK, Cardella J, Barr JD, Mathis JM, Sanchez O, Schwartzberg MS, Swan TL and Sacks D; SIR Standards of Practice Committee: Society of Interventional radiology quality improvement guidelines for percutaneous vertebroplasty. J Vasc Interv Radiol 14: 827-831, 2003.

16. Helmberger T, Bohndorf K, Hierholzer J, Noldge G, Vorwerk D and German Radiological Society: Guidelines of the german radiological society for percutaneous vertebroplasty. Radiologe 43: 703-708, 2003 (In German).

17. Quinn RH, Randall RL, Benevenia J, Berven SH and Raskin KA: Contemporary management of metastatic bone disease: Tips and tools of the trade for general practitioners. J Bone Joint Surg Am 95: 1887-1895, 2013.

18. Dushyanthen S, Cossigny DA and Quan GM: The osteoblastic and osteoclastic interactions in spinal metastases secondary to prostate cancer. Cancer Growth Metastasis 6: 61-80, 2013.

19. Ortiz A and Lin SH: Osteolytic and osteoblastic bone metastases: Two extremes of the same spectrum? Recent Results Cancer Res 192: 225-233, 2012

20. Guise TA, Yin JJ and Mohammad KS: Role of endothelin-1 in osteoblastic bone metastases. Cancer 97 (Suppl 3): S779-S784, 2003.

21. Kasperk CH, Börcsök I, Schairer HU, Schneider U, Nawroth PP, Niethard FU and Ziegler R: Endothelin-1 is a potent regulator of human bone cell metabolism in vitro. Calcif Tissue Int 60 368-374, 1997.

22. Johnson RW and Suva LJ: Hallmarks of bone metastasis. Calcif Tissue Int 102: 141-151, 2018

23. Yi B, Williams PJ, Niewolna M, Wang Y and Yoneda $\mathrm{T}$ : Tumor-derived platelet-derived growth factor-BB plays a critical role in osteosclerotic bone metastasis in an animal model of human breast cancer. Cancer Res 62: 917-923, 2002
24. Achbarou A, Kaiser S, Tremblay G, Ste-Marie LG, Brodt P, Goltzman D and Rabbani SA: Urokinase overproduction results in increased skeletal metastasis by prostate cancer cells in vivo. Cancer Res 54: 2372-2377, 1994.

25. Cramer SD, Chen Z and Peehl DM: Prostate specific antigen cleaves parathyroid hormone-related protein in the PTH-like domain: Inactivation of PTHrP-stimulated cAMP accumulation in mouse osteoblasts. J Urol 156: 526-531, 1996.

26. Maeda H, Koizumi M, Yoshimura K, Yamauchi T, Kawai T and Ogata E: Correlation between bone metabolic markers and bone scan in prostatic cancer. J Urol 157: 539-543, 1997.

27. Diel IJ, Solomayer EF, Costa SD, Gollan C, Goerner R, Wallwiener D, Kaufmann M and Bastert G: Reduction in new metastases in breast cancer with adjuvant clodronate treatment. N Engl J Med 339: 357-363, 1998.

28. Saad F, Gleason DM, Murray R, Tchekmedyian S, Venner P, Lacombe L, Chin JL, Vinholes JJ, Goas JA and Chen B; Zoledronic Acid Prostate Cancer Study Group: A randomized, placebo-controlled trial of zoledronic acid in patients with hormone-refractory metastatic prostate carcinoma. J Natl Cancer Inst 94: 1458-1468, 2002.

29. Xu SF, Adams B, Yu XC and Xu M: Denosumab and giant cell tumour of bone-a review and future management considerations. Curr Oncol 20: e442-e447, 2013.

30. Sousa $S$ and Clézardin P: Bone-targeted therapies in cancer-induced bone disease. Calcif Tissue Int 102: 227-250, 2018.

31. Dorff TB and Agarwal N: Bone-targeted therapies to reduce skeletal morbidity in prostate cancer. Asian J Androl 20: 215-220, 2018.

32. McClung MR, Brown JP, Diez-Perez A, Resch H, Caminis J, Meisner P, Bolognese MA, Goemaere S, Bone HG, Zanchetta JR, et al: Effects of 24 months of treatment with romosozumab followed by 12 months of denosumab or placebo in postmenopausal women with low bone mineral density: A randomized, double-blind, phase 2, parallel group study. J Bone Miner Res 33: 1397-1406, 2018.

33. Tekin SB, Karslı B, Büyükbebeci O, Demir İH, Gökalp AY and Kilınçoğlu V: How do vertebroplasty and kyphoplasty affect the quality of life of patients with multiple myeloma spinal metastasis? Eur J Orthop Surg Traumatol 30: 1447-1451, 2020.

34. Qi L, Li C, Wang N, Lian H, Lian M, He B and Bao G: Efficacy of percutaneous vertebroplasty treatment of spinal tumors: A meta-analysis. Medicine (Baltimore) 97: e9575, 2018.

35. Health Quality Ontario: Vertebral augmentation involving vertebroplasty or kyphoplasty for cancer-related vertebral compression fractures: An economic analysis. Ont health Technol Assess Ser 16: 1-34, 2016.

36. Peh WC and Gilula LA: Percutaneous vertebroplasty: An update. Semin Ultrasound CT MR 26: 52-64, 2005.

37. Wolman DN and Heit JJ: Recent advances in vertebral augmentation for the treatment of vertebral body compression fractures. Curr Phys Med Rehabilitation Rep 5: 1-14, 2017.

38. Wang H, Sribastav SS, Ye F, Yang C, Wang J, Liu H and Zheng Z: Comparison of percutaneous vertebroplasty and balloon kyphoplasty for the treatment of single level vertebral compression fractures: A meta-analysis of the literature. Pain Physician 18: 209-222, 2015

39. Chen L, Ni RF, Liu SY, Liu YZ, Jin YH, Zhu XL, Zou JW and Xiao XS: Percutaneous vertebroplasty as a treatment for painful osteoblastic metastatic spinal lesions. J Vasc Interv Radiol 22: 525-528, 2011.

40. Calmels V, Vallee JN, Rose M and Chiras J: Osteoblastic and mixed spinal metastases: evaluation of the analgesic efficacy of percutaneous vertebroplasty. AJNR Am J Neuroradiol 28: 570-574, 2007.

41. Chen G, Luo ZP, Zhang H, Nalajala B and Yang H: Percutaneous kyphoplasty in the treatment of painful osteoblastic metastatic spinal lesions. J Clin Neurosci 20: 948-950, 2013.

42. Mattei TA, Mendel E and Bourekas EC: Vertebral compression fractures in patients under treatment with denosumab: A contraindication for percutaneous vertebroplasty? Spine J 14: e29-e35, 2014.

43. Chow E, Ding K, Parulekar WR, Wong RK, van der Linden YM, Roos D, Hartsell WF, Hoskin P, Wu JS, Nabid A, et al: Revisiting classification of pain from bone metastases as mild, moderate, or severe based on correlation with function and quality of life. Support Care Cancer 24: 1617-1623, 2016.

44. Wang Y, Liu H, Pi B, Yang H, Qian Z and Zhu X: Clinical evaluation of percutaneous kyphoplasty in the treatment of osteolytic and osteoblastic metastatic vertebral lesions. Int J Surg 30: $161-165,2016$. 
45. Costa L, Badia X, Chow E, Lipton A and Wardley A: Impact of skeletal complications on patients' quality of life, mobility, and functional independence. Support Care Cancer 16: 879-889, 2008.

46. Bedard G, Zeng L, Poon M, Lam H, Lauzon N and Chow E: Comparison of the EORTC QLQ-BM22 and the BOMET-QOL quality of life questionnaires in patients with bone metastases. Asia Pac J Clin Oncol 10: 118-123, 2014.
47. Nieuwenhuijse MJ, Van Erkel AR and Dijkstra PD: Cement leakage in percutaneous vertebroplasty for osteoporotic vertebral compression fractures: Identification of risk factors. Spine J 11: 839-848, 2011.

(c) () $\Theta$ This work is licensed under a Creative Commons EY NG ND Attribution-NonCommercial-NoDerivatives 4.0 International (CC BY-NC-ND 4.0) License. 